\title{
Tribute to Guido Weiss on his Ninetieth Birthday
}

\author{
Steven G. Krantz ${ }^{1}$
}

Accepted: 10 October 2020 / Published online: 14 January 2021

(c) Mathematica Josephina, Inc. 2021

Guido L. Weiss was one of the important harmonic analysts of the twentieth century. A student of Antoni Zygmund, Guido was a master of all parts of harmonic analysisfrom Fourier series to Lie theory to singular integrals to Hardy spaces to wavelets. He had many strong collaborators, including Stein, Taibleson, Rochberg, Coifman, Christ, Kenig, Meyer and a host of others.

I have been Guido's colleague for nearly thirty-five years. I have always been struck by the fact that, nearly every year, he would have one or more postdocs and one or more Ph.D. students. Guido had $33 \mathrm{Ph}$.D. students altogether and he mentored innumerable young mathematicians. He collaborated with most of them. His passion and his joy in life were communicating and sharing mathematics.

Guido wrote 106 papers and 7 books. A prolific output by any measure. Some of his books, such as the book on Fourier Analysis jointly authored with E. M. Stein, stand as paragons in the field. His book on the atomic theory with R. R. Coifman is also very significant. Guido was a gifted writer, and it is always a pleasure to read one of his books or papers.

Guido was very well read and had encyclopedic knowledge of topics both obvious and exotic. He spoke about seven languages. He could often be heard on the telephone chatting away in some foreign tongue. He had friends and colleagues and collaborators all over the world.

Guido is a social creature, and it was always a pleasure to share a meal or a tennis game or some mathematics with him. He was spirited and enthusiastic and dynamic. He lives a quieter life now, but he has many powerful memories.

Guido Weiss has had a signficant influence on the lives of all analysts. He will be remembered warmly and respectfully for many years.

Steven G. Krantz

Editor-in-Chief

Journal of Geometric Analysis

Publisher's Note Springer Nature remains neutral with regard to jurisdictional claims in published maps and institutional affiliations.

Steven G. Krantz

sgkrantz@gmail.com

1 Washington University, St. Louis, MO, USA 